\title{
Association between frailty and short- and long-term outcomes among critically ill patients: a multicentre prospective cohort study
}

\author{
Sean M. Bagshaw MD, H. Thomas Stelfox MD, Robert C. McDermid MD, Darryl B. Rolfson MD, \\ Ross T. Tsuyuki PharmD, Nadia Baig BSc, Barbara Artiuch MD, Quazi Ibrahim MSc, Daniel E. Stollery MD, \\ Ella Rokosh MD, Sumit R. Majumdar MD
}

\begin{abstract}
Background: Frailty is a multidimensional syndrome characterized by loss of physiologic and cognitive reserves that confers vulnerability to adverse outcomes. We determined the prevalence, correlates and outcomes associated with frailty among adults admitted to intensive care.

Methods: We prospectively enrolled 421 critically ill adults aged 50 or more at 6 hospitals across the province of Alberta. The primary exposure was frailty, defined by a score greater than 4 on the Clinical Frailty Scale. The primary outcome measure was in-hospital mortality. Secondary outcome measures included adverse events, 1-year mortality and quality of life.
\end{abstract}

Results: The prevalence of frailty was $32.8 \%$ (95\% confidence interval $[\mathrm{Cl}] 28.3 \%-37.5 \%$ ). Frail patients were older, were more likely to be female, and had more comorbidities and greater functional dependence than those who were not frail. In-hospital mortality was higher among frail patients than among nonfrail patients (32\% v. $16 \%$; adjusted odds ratio [OR] 1.81, 95\% Cl 1.09-3.01) and remained higher at 1 year (48\% v. $25 \%$; adjusted hazard ratio $1.82,95 \% \mathrm{Cl} 1.28-2.60)$. Major adverse events were more common among frail patients (39\% v. $29 \%$; OR $1.54,95 \%$ Cl $1.01-$ 2.37). Compared with nonfrail survivors, frail survivors were more likely to become functionally dependent $(71 \%$ v. $52 \%$; OR $2.25,95 \% \mathrm{Cl}$ 1.03-4.89), had significantly lower quality of life and were more often readmitted to hospital $(56 \%$ v. $39 \%$; OR $1.98,95 \%$ Cl $1.22-3.23)$ in the 12 months following enrolment.

Interpretation: Frailty was common among critically ill adults aged 50 and older and identified a population at increased risk of adverse events, morbidity and mortality. Diagnosis of frailty could improve prognostication and identify a vulnerable population that might benefit from follow-up and intervention.
Competing interests: Ross Tsuyuki has served on advisory boards for Bristol-Myers Squibb, PharmaSmart International and Abbott Laboratories, and a data monitoring board for dabigatran studies for Boehringer Ingelheim; he has received consultant fees from Merck; and his institution has received grants from Sanofi and AstraZeneca. No competing interests were declared by the other authors.

This article has been peer reviewed.

Correspondence to: Sean Bagshaw, bagshaw@ualberta.ca

CMAJ 2014. DOI:10.1503 /cmaj.130639
$\mathrm{F}$ railty is a term widely used to describe a multidimensional syndrome characterized by the loss of physiologic and cognitive reserves that gives rise to heightened vulnerability to adverse outcomes. ${ }^{1,2}$ Adverse events associated with frailty include incident falls, susceptibility to acute illness, perioperative complications, unplanned hospital admissions, disability, need for institutional care, and death. ${ }^{3-10}$ Frailty has substantial implications for quality of life, functional autonomy and health services utilization, but it has not been evaluated in critically ill patients.

The development of critical illness may lead to frailty in vulnerable patients. Critical illness may also be a key factor impeding recovery and functional autonomy in those already considered to be frail. ${ }^{11}$ We hypothesized that frailty would identify vulnerable patients who are less likely to tolerate critical illness, who are more susceptible to complications and death, and who are less likely to fully recover after critical illness over the short or long term. We further hypothesized that this information would translate into more accurate prognostication, which might improve decision-making for frail patients and their families. To test these hypotheses, we performed a prospective multi-centre study in an unselected cohort of critically ill patients.

\section{Methods}

\section{Study design and population}

This was a multicentre prospective cohort study. The study population comprised adults admitted to 1 of 6 participating intensive care units (ICUs) between Feb. 1, 2010, and July 31, 2011. The ICUs were located in 2 tertiary care academic hospitals and 4 community hospitals in the province of 
Alberta (Appendix 1, available at www.cmaj.ca /lookup/suppl/doi:10.1503/cmaj.130639/-/DC1). These hospitals were selected to represent the province and capture academic and community settings to minimize selection bias.

Patients were included if they were aged 50 years or more (based on the low prevalence of frailty among younger patients ${ }^{12}$ ), were admitted to a participating ICU and were able to provide consent. Patients were excluded if their expected ICU stay or survival was less than 24 hours or if they had previously been enrolled in the study. Consecutive participants were identified by daily screening of new ICU admissions.

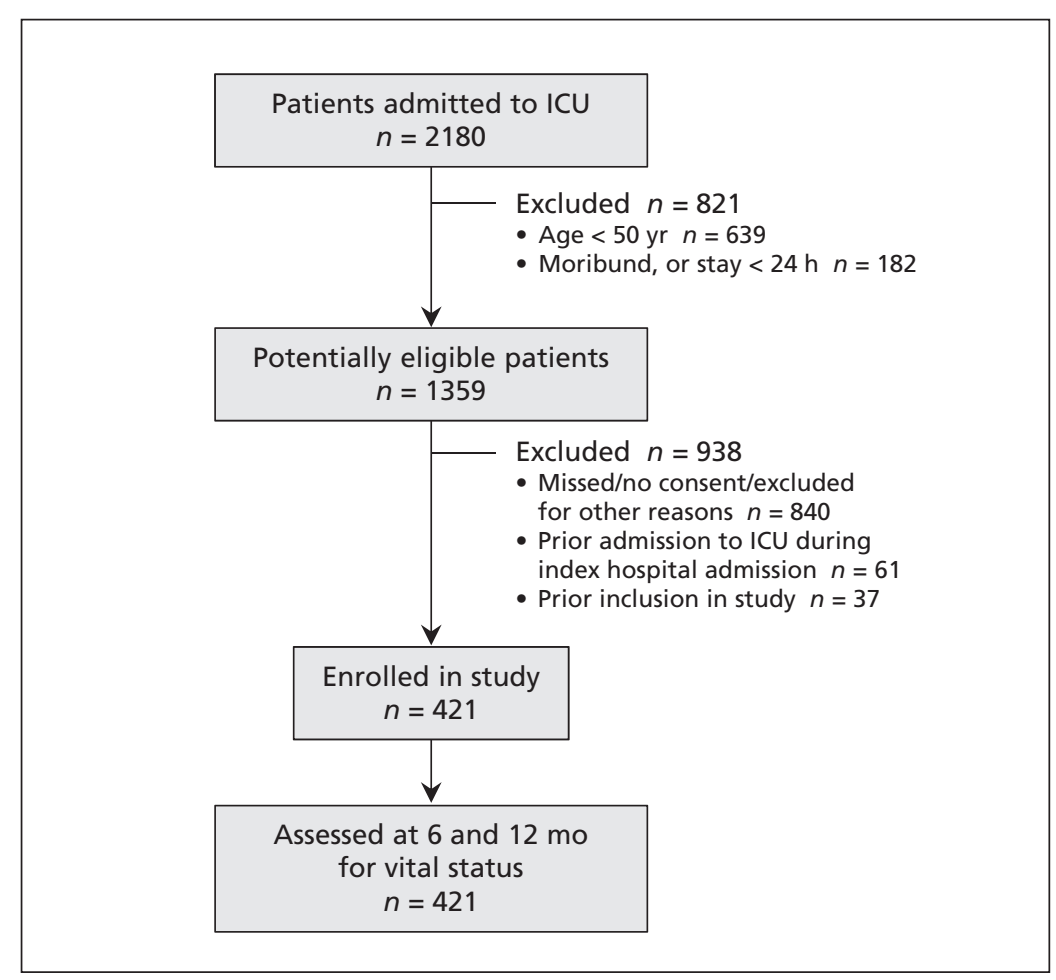

Figure 1: Selection of critically ill patients for the study cohort.

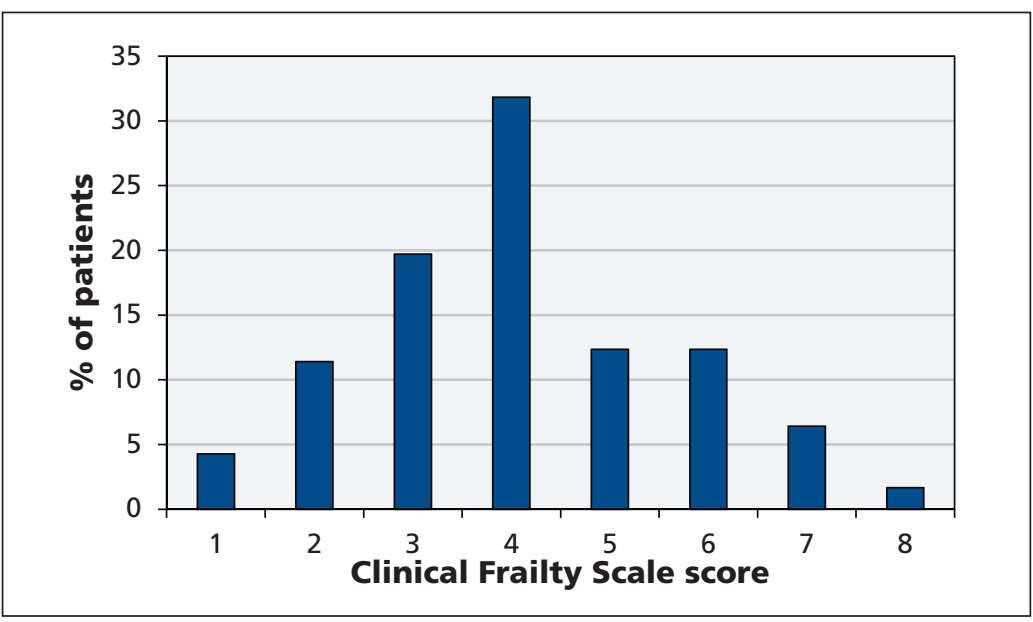

Figure 2: Distribution of Clinical Frailty Scale scores and prevalence of frailty (score $>4$ ) among the participants.
All participants or their surrogates provided informed consent. The study was approved by the Health Research Ethics Board at the University of Alberta and the Conjoint Health Research Ethics Board at the University of Calgary.

\section{Determination of frailty}

Frailty was defined with the use of the Canadian Study on Health and Aging Clinical Frailty Scale, a well-validated 9-point assessment tool designed to quantify frailty (Appendix 2, available at www.cmaj.ca/lookup/suppl/doi:10.1503 /cmaj.130639/-/DC1). ${ }^{3}$ Trained research coordinators masked to the study hypotheses determined the Clinical Frailty Scale scores by interviewing participants or surrogates and reviewing each participant's medical record. We considered patients to be frail if they had a score greater than 4 (which represents mild, moderate, severe or very severe frailty ${ }^{3}$ ) immediately before the index hospital admission.

\section{Outcome measures}

The primary outcome measure was all-cause inhospital mortality. Secondary outcome measures included the following: death in ICU, hospital or at 6 months; health-related quality of life at 6 and 12 months (as measured by the 12-item ShortForm Health Survey [SF-12] ${ }^{13}$ and the EuroQol Health Questionnaire [EQ-5D]); ${ }^{14}$ intensity of treatment in the ICU (as determined by whether vasoactive therapy, mechanical ventilation, renal replacement therapy or blood transfusion was provided); major adverse events (defined as a composite of serious medication errors, self-extubation or re-intubation, or nosocomial infection [e.g., catheter-related bloodstream infection] during the hospital stay); and health services utilization (as measured by durations of stay in ICU and hospital as well as readmission to hospital within 12 months after enrolment).

\section{Other covariables}

At enrolment, the trained research coordinators collected information through interviews with the participants (or surrogates) and chart reviews. The collected data included age, sex, race/ethnicity, education level, marital status, ability to perform instrumental and functional activities of daily living, comorbid conditions and degree of comorbidity (e.g., defined according to Elixhauser score ${ }^{15,16}$ ), number of prescription medications, ${ }^{17}$ number of hospital and ICU admissions in the year before enrolment, source of transfer to ICU (e.g., ward, emergency department, other hospital, operating theatre), illness severity (e.g., defined according to Acute Physiology and Chronic Health Evaluation [APACHE] II score ${ }^{18}$ ), and presence and severity 
of organ dysfunction (e.g., defined according to Sequential Organ Failure Assessment [SOFA] score $^{19}$ ). In addition, the research coordinators determined whether limitations in the provision of ICU-specific, life-sustaining therapy (e.g., cardiopulmonary resuscitation, advanced cardiac life support, mechanical ventilation, use of vasoactives and renal replacement therapy) were documented in the medical record.

The research coordinators contacted surviving participants by telephone at 6 and 12 months after enrolment to determine vital status, disposition and health-related quality of life using a scripted text. ${ }^{20,21}$

Data were captured on standardized case report forms and entered into an electronic database.

\section{Statistical analysis}

Based on data from a pilot study involving 50 patients, we expected a prevalence of frailty of $30 \%$ (unpublished data). To confirm this magnitude of prevalence within 5\% binomial confidence limits, we required a sample of at least 400 participants. With an anticipated 1-year mortality of 40\% (160 events), this sample size would permit up to 16 covariates in multivariable models of 1-year mortality with a 2-tailed $\alpha$ value of 0.05 and would have at least $80 \%$ power to detect $15 \%$ differences between frail and nonfrail participants.

Descriptive statistics according to frailty status were tabulated, and univariable comparisons of means, medians and proportions were performed. Kaplan-Meier survival curves were constructed, and multivariable logistic regression (in-hospital mortality) and Cox regression (1-yr mortality) analyses were used to determine the association between frailty and mortality. The models were adjusted for potential confounding factors, which were included based on their clinical importance, evidence from the literature or their significance at $p<0.20$ in the univariable analysis.

For the logistic regression analysis, model fit and calibration were assessed with the HosmerLemeshow goodness-of-fit test and the $\mathrm{C}$ statistic. For the Cox regression analysis, time-dependent covariates and $\log (-\log )$ plots were used to test for violations of the proportional hazards assumptions; no violations were observed. Analogous analyses were undertaken for the other study outcomes.

Using the Student $t$ test, we compared participants' health-related quality-of-life measures at 6 and 12 months against normative SF-12 and EQ$5 \mathrm{D}$ data for the general population in Alberta. ${ }^{22}$

A $p$ value of less than 0.05 was considered statistically significant for all comparisons. All analyses were performed with the use of Stata 11.2 (StataCorp).
Table 1: Baseline characteristics of patients admitted to intensive care unit (ICU), by frailty status

\begin{tabular}{|c|c|c|c|}
\hline \multirow[b]{2}{*}{ Characteristic } & \multicolumn{2}{|c|}{$\begin{array}{l}\text { Group; no. (\%) } \\
\text { of patients* }\end{array}$} & \multirow[b]{2}{*}{$p$ valuet } \\
\hline & $\begin{array}{c}\text { Frail } \\
n=138\end{array}$ & $\begin{array}{l}\text { Not frail } \\
n=283\end{array}$ & \\
\hline Age, yr, mean \pm SD & $69 \pm 10$ & $66 \pm 10$ & 0.007 \\
\hline Sex, female & $66(47.8)$ & $97(34.3)$ & 0.007 \\
\hline Race, white & $114(82.6)$ & $240(84.8)$ & 0.6 \\
\hline \multicolumn{4}{|l|}{ Marital status } \\
\hline Married or common law & $87(63.0)$ & $189(66.8)$ & 0.45 \\
\hline Never married & 4 (2.9) & $23(8.1)$ & 0.03 \\
\hline Widowed & $25(18.1)$ & $28(9.9)$ & 0.02 \\
\hline Less than high school education & $39(28.3)$ & $54(19.1)$ & 0.03 \\
\hline Residence & & & $<0.001$ \\
\hline Living at home independently & $58(42.0)$ & $244(86.2)$ & \\
\hline Living at home with help & $64(46.4)$ & $35(12.4)$ & \\
\hline Other $¥$ & $9(6.5)$ & $3(1.2)$ & \\
\hline \multicolumn{4}{|l|}{$\begin{array}{l}\text { Able to perform activity } \\
\text { independently§ }\end{array}$} \\
\hline Taking a bath & $79(57.2)$ & $274(96.8)$ & $<0.001$ \\
\hline Walking & $77(55.8)$ & $259(91.5)$ & $<0.001$ \\
\hline Taking medications & $90(65.2)$ & $270(95.4)$ & $<0.001$ \\
\hline Managing own finances & $102(73.9)$ & $273(96.5)$ & $<0.001$ \\
\hline $\begin{array}{l}\text { Elixhauser comorbidity score, } \\
\text { mean } \pm \text { SD }\end{array}$ & $10 \pm 9$ & $7 \pm 7$ & $<0.001$ \\
\hline $\begin{array}{l}\text { No. of prescription medications, } \\
\text { mean } \pm \text { SD }\end{array}$ & $8.9 \pm 5$ & $5.5 \pm 4$ & $<0.001$ \\
\hline Prior hospital admissionף & $77(55.8)$ & $99(35.0)$ & $<0.001$ \\
\hline Prior ICU admissionף & $37(26.8)$ & $63(22.3)$ & 0.3 \\
\hline Source of transfer to ICU & & & 0.5 \\
\hline Ward & $72(52.2)$ & $167(59.0)$ & \\
\hline Emergency department & $40(29.0)$ & $72(25.4)$ & \\
\hline Another hospital & $24(17.4)$ & $39(13.8)$ & \\
\hline Other & $2(1.4)$ & $5 \quad(1.8)$ & \\
\hline Postoperative ICU admission** & $34(24.6)$ & $108(38.2)$ & 0.006 \\
\hline Cardiac arrest†† & $10(7.2)$ & $21(7.4)$ & 0.9 \\
\hline Rapid response teamt† & $36(26.1)$ & $74(26.1)$ & 0.9 \\
\hline APACHE II score, $†+$ mean \pm SD & $21 \pm 7$ & $19 \pm 7$ & $<0.001$ \\
\hline SOFA score, $\dagger+$ mean \pm SD & $8 \pm 4$ & $7 \pm 4$ & 0.1 \\
\hline Limitation of medical therapy $\ddagger$ & $47(34.1)$ & $34(12.0)$ & $<0.001$ \\
\hline
\end{tabular}

Note: $\mathrm{APACHE}=$ Acute Physiology and Chronic Health Evaluation, CSHA = Canadian Study of Health and Ageing, SD = standard deviation, SOFA = Sequential Organ Failure Assessment.

*Unless stated otherwise.

$t t$ test for comparisons of continuous data and $\chi^{2}$ test for comparisons of categorical data. $\neq$ Continuing care facility, subacute care facility or other.

$\S$ Score of 0 on the CSHA Function Scale.

ПII the year before enrolment.

** Surgery within 48 hours before ICU admission.

t+At time of ICU admission.

¥¥Limitation in the provision of ICU-specific life-sustaining therapy (e.g., cardiopulmonary resuscitation, advanced cardiac life support, mechanical ventilation, use of vasoactives, renal replacement therapy) documented in the medical record. 


\section{Results}

A total of 421 patients were enrolled in our study (Figure 1). Their mean age ( \pm standard deviation) was $67 \pm 10$ years; $163(39 \%)$ were female, and $402(95 \%)$ were living at home independently or with assistance. At the time of ICU admission, the mean APACHE II score was $20 \pm 7$, the SOFA score was $7 \pm 4$, and 142 (34\%) of the participants had had surgery within 48 hours before

\begin{tabular}{|c|c|c|c|}
\hline \multirow[b]{2}{*}{ Variable } & \multicolumn{2}{|c|}{ Group; no. (\%) of patients } & \multirow[b]{2}{*}{$p$ value* } \\
\hline & $\begin{array}{c}\text { Frail } \\
n=138\end{array}$ & $\begin{array}{c}\text { Not frail } \\
n=283\end{array}$ & \\
\hline Mechanical ventilation & $122(88.4)$ & $240(84.8)$ & 0.3 \\
\hline Re-intubation & $17(12.3)$ & $30(10.6)$ & 0.6 \\
\hline Tracheostomy & $18(13.0)$ & $35(12.4)$ & 0.9 \\
\hline Vasoactive medications & $83(60.1)$ & $146(51.6)$ & 0.1 \\
\hline Renal replacement therapy & $14(10.1)$ & $33(11.7)$ & 0.6 \\
\hline Blood transfusion & $57(41.3)$ & $113(39.9)$ & 0.8 \\
\hline Surgical procedure or re-operation & $26(18.8)$ & $63(22.3)$ & 0.4 \\
\hline
\end{tabular}

Table 3: Clinical outcomes, by frailty status

\begin{tabular}{|c|c|c|c|}
\hline \multirow[b]{2}{*}{ Outcome } & \multicolumn{2}{|c|}{$\begin{array}{l}\text { Group; no. (\%) } \\
\text { of patients* }\end{array}$} & \multirow{2}{*}{$\begin{array}{c}\text { Association, } \\
\text { OR }(95 \% \mathrm{Cl}) \text { or } \\
\text { difference in } \\
\text { medians ( } p \text { valuet) }\end{array}$} \\
\hline & $\begin{array}{c}\text { Frail } \\
n=138\end{array}$ & $\begin{array}{l}\text { Not frail } \\
n=283\end{array}$ & \\
\hline Adverse event $\ddagger$ & $54(39.1)$ & $83(29.3)$ & $1.54(1.01-2.37)$ \\
\hline \multicolumn{4}{|l|}{ Death } \\
\hline In ICU & $16(11.6)$ & $27 \quad(9.5)$ & $1.37(0.72-2.62)$ \\
\hline In hospital & $44(31.9)$ & $45(15.9)$ & $1.81(1.09-3.01)$ \\
\hline \multicolumn{4}{|l|}{ Duration of stay, $d$, median (IQR) } \\
\hline In ICU & $7(4-13)$ & $6(3-10)$ & $1 \mathrm{~d}(0.02)$ \\
\hline In hospital & $30(10-64)$ & $18(10-40)$ & $12 d(0.02)$ \\
\hline Discharge disposition§ & $n=91$ & $n=235$ & \\
\hline Home, living independently & $20(22.0)$ & $104(44.3)$ & $0.35(0.20-0.61)$ \\
\hline Home, living with help & $33(36.3)$ & $58(24.7)$ & $1.67(1.00-2.81)$ \\
\hline Otherף & $38(41.8)$ & $73(31.1)$ & $1.51(0.92-2.48)$ \\
\hline Discharged newly dependent** & $24(70.6)$ & $96(51.6)$ & $2.25(1.03-4.89)$ \\
\hline Hospital readmission§ & $51(56.0)$ & $92(39.1)$ & $1.98(1.22-3.23)$ \\
\hline \multicolumn{4}{|c|}{$\begin{array}{l}\text { Note: } \mathrm{Cl}=\text { confidence interval, ICU = intensive care unit, OR = odds ratio. } \\
\text { *Unless stated otherwise. } \\
\text { tMann-Whitney test. } \\
\text { tComposite of medication errors, self-extubation/reintubation, nosocomial infection, death. } \\
\text { \$Among } 91 \text { frail and } 235 \text { nonfrail patients for whom data on discharge disposition and on } \\
\text { hospital readmission within } 12 \text { mo after discharge could be ascertained (data missing, } n=1 \\
\text { per group; in hospital at end of follow-up, } n=2 \text { per group). } \\
\text { ๆContinuing care facility, subacute care facility or other. } \\
\text { **Among } 34 \text { frail and } 186 \text { nonfrail patients who were living independently at baseline. }\end{array}$} \\
\hline
\end{tabular}

the admission. There were no clinically important or statistically significant differences in baseline sociodemographic characteristics or illness severity between enrolled participants and patients who were eligible but were not enrolled (Appendix 3, available at www.cmaj.ca/lookup/suppl /doi:10.1503/cmaj.130639/-/DC1).

Overall, 138 of the 421 participants were considered to be frail (Clinical Frailty Scale score $>4$ ), for a frailty prevalence of $32.8 \%$ (95\% confidence interval [CI] 28.3\%-37.5\%). The median frailty score was 4 (interquartile range 3-5) (Figure 2). Compared with nonfrail patients, frail patients were older, were more likely to be female, had more comorbid disease and greater functional dependence, and tended to have fewer social supports (Table 1).

Frail patients were more likely than nonfrail patients to be admitted for nonsurgical reasons and to have higher APACHE II scores, although baseline and daily SOFA scores were not significantly different between the two groups (Table 1). Irrespective of frailty, all patients received similar intensity of treatment (Table 2). Compared with nonfrail patients, those with frailty were more likely to have limitations of medical therapy at ICU admission (34\% v. 12\%; $p<0.001)$.

Mortality during the ICU stay did not differ according to frailty, but in-hospital mortality was higher among frail patients $(32 \%$ v. 16\%; adjusted odds ratio [OR] 1.81, 95\% CI 1.093.01) (Table 3). In the multivariable analysis, over the 12-month follow-up period, frailty was independently associated with all-cause mortality $(48 \%$ v. $25 \%$; adjusted hazard ratio [HR] $1.82 ; 95 \%$ CI 1.28-2.60). In a dose-dependent manner, an increasing frailty score (rather than the cutpoint of 4 used in the primary analysis) was independently associated with incremental mortality in adjusted analyses (Figures 3 and 4).

Among the survivors, frailty was associated with significantly longer durations of stay in both ICU and hospital (Table 3). Frail patients also had a 1.5-fold higher odds of major adverse events during their hospital stay compared with their nonfrail counterparts (OR 1.54, 95\% CI 1.01-2.37). In the 12 months after hospital discharge, frail patients had a greater rate of hospital readmission than nonfrail patients had $(56 \%$ v. 39\%; OR 1.98, 95\% CI 1.22-3.23).

After hospital discharge, frail patients were less likely than nonfrail patients to be living at home independently ( $22 \%$ v. $44 \%$; OR $0.35,95 \%$ CI 0.20-0.61) (Table 3). This difference persisted at 6 months $(28 \%$ v. $61 \%$; OR $0.25,95 \%$ CI $0.14-0.43)$ and at 12 months (31\% v. 67\%; OR $0.22,95 \%$ CI $0.12-0.40)$. Among survivors who were living independently at baseline, frail 
patients were more likely than nonfrail patients to become functionally dependent (71\% v. 52\%; OR $2.25,95 \%$ CI 1.03-4.89) (Table 3). In a sensitivity analysis, this association was stronger when stratified by a baseline frailty score of more than 5 or of 3 or lower $(78 \%$ v. $46 \%$; OR $4.14,95 \%$ CI 1.34-12.73). Health-related quality of life was generally lower among the frail patients than among the nonfrail patients at 6 and 12 months, and across all physical and mental health domains; however, both groups had lower healthrelated quality of life compared with the general population of Alberta $^{22}$ (Table 4).

\section{Interpretation}

In this prospective multicentre study of a representative cohort of critically ill patients over the age of 50 , we found that frailty was common, affecting one-third of the participants. Frail patients differed from nonfrail patients in many sociodemographic and clinical characteristics, including having a greater burden of comorbid illness and functional impairment at ICU admission. Despite both groups having similar treatment intensity, frail patients were more likely to experience adverse events, had longer lengths of stay in ICU and hospital, and were more likely to die while in hospital and within 12 months after admission. Among survivors, frail patients were more likely than nonfrail patients to have new functional dependence at hospital discharge and had higher rates of hospital readmission. There was a similar disadvantage for frail patients for worse health-related quality of life across all domains measured. These associations were stronger with increasing severity of frailty and persisted even after adjustment for sociodemographic factors, premorbid health status, comorbidities and illness severity.

Our data suggest that frailty can be measured in patients admitted to the ICU using a simple bedside assessment tool and is an important prognostic factor in both the short and long term. ${ }^{23}$ Similar to acute care hospital admission contributing to an increased likelihood of cognitive impairment, an episode of critical illness may have a sustained

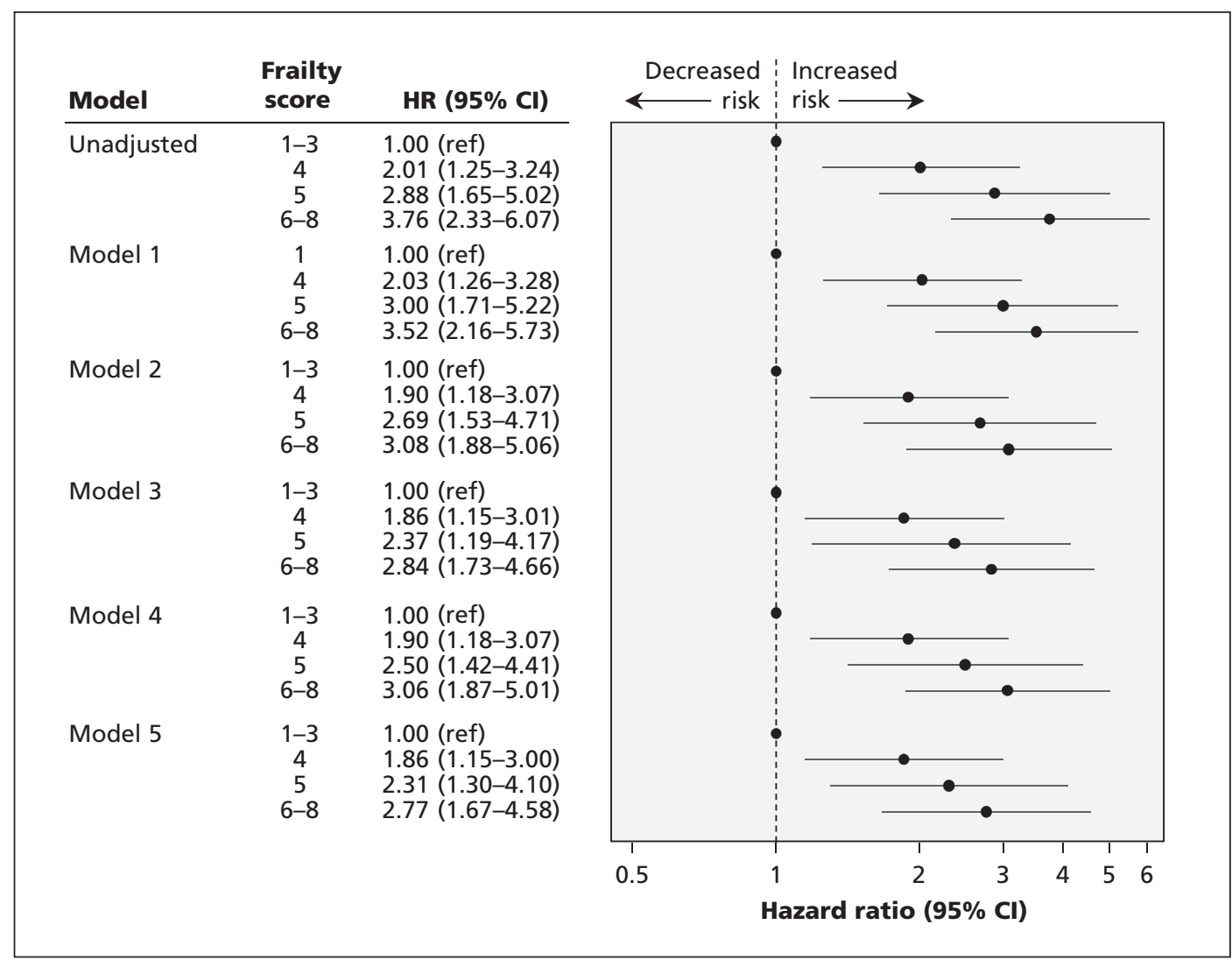

Figure 3: Adjusted hazard ratios for death within 12 months after admission to an intensive care unit, stratified by Clinical Frailty Scale score (score $>4$ indicates frailty). Hazard ratios greater than 1.0 indicate an increased risk of death. The models were adjusted as follows: model 1 for age and sex; model 2 for age, sex and Elixhauser score (comorbidity indicator); model 3 for age, sex, Elixhauser score and non-age-specific Acute Physiology and Chronic Health Evaluation (APACHE) II score (illness severity); model 4 for age, sex, Elixhauser score and Sequential Organ Failure Assessment (SOFA) score (presence and severity of organ dysfunction); and model 5 for age, sex, Elixhauser score, non-age-specific APACHE II score and hospital type (tertiary care/academic v. community). $\mathrm{Cl}$ = confidence interval, ref = reference group. 
impact on the capacity for frail patients to recover and regain or maintain functional independence. ${ }^{24,25}$

In the context of critical illness, a degree of frailty seems to identify a vulnerable population whose risk of poor outcomes is heightened. This risk may be further exacerbated by frail patients having fewer social supports, as shown in our study. The interplay of frailty and critical illness may provide an opportunity to target and evaluate interdisciplinary programs of care and rehabilitation, with the aim of improving recovery and avoiding mortality, functional dependence, reduced quality of life and added health service utilization..$^{23,26,27}$ For frail critically ill patients, such an integrated program may have elements addressing the minimization of unnecessary sedation, ${ }^{28}$ screening for delirium, ${ }^{29}$ early assessment for weaning from mechanical ventilation, nutritional support, ${ }^{30}$ medication reconciliation ${ }^{31}$ and early mobilization. ${ }^{32,33}$ In addition, the measurement and diagnosis of frailty could translate

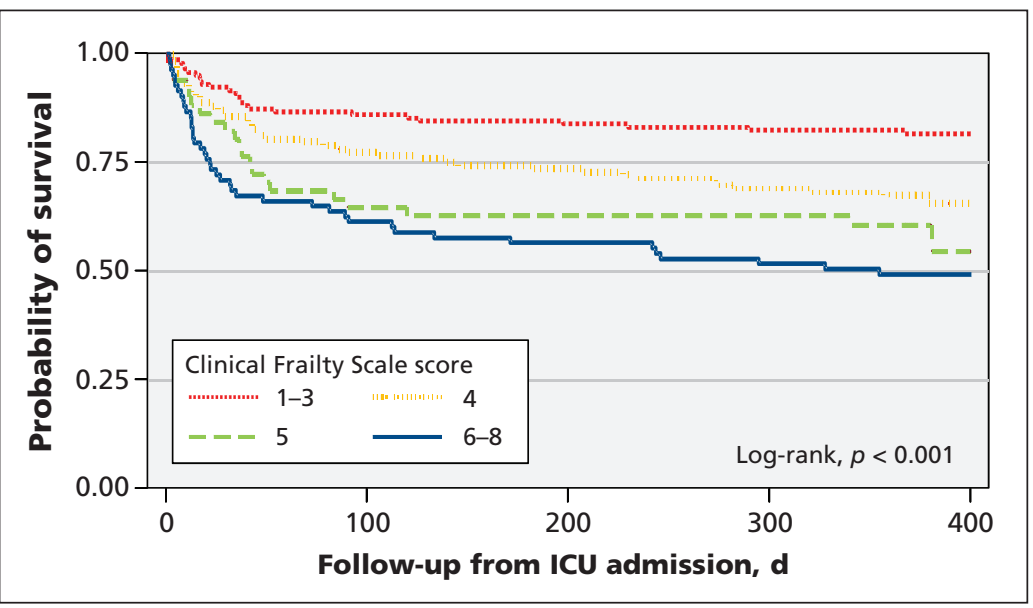

Figure 4: Kaplan-Meier survival curves stratified by Clinical Frailty Scale score. into better informed decision-making for patients, their families and clinicians around issues related to the provision of advanced life support and designation of goals of care.

Frailty is generally viewed as an age-associated loss of reserve across multiple physiologic and cognitive systems that give rise to susceptibility to adverse events. ${ }^{1,2}$ A variety of operational definitions have been applied to encapsulate the frail state across clinical contexts; however, none has been used to describe frailty among a generalizable cohort with critical illness. ${ }^{34}$ Similarly, other measures of performance status have been integrated into studies involving critically ill patients, generally for risk adjustment; however, they have not been evaluated in the context of frailty. ${ }^{35,36}$ Data from the Canadian National Population Health Survey showed that the prevalence of frailty was about $7 \%$ and that it increased exponentially with age. ${ }^{4}$ In a vulnerable cohort of older outpatients, the prevalence of frailty was $59 \% .^{3}$ We found frailty in $33 \%$ of the critically ill patients enrolled in our study, an estimate between the extremes of the general population and an older outpatient population. Notably, our cohort was relatively young compared with these cohorts, implying the susceptibility to critical illness may be "age-shifted" in those with frailty. This suggests that an episode of critical illness in a frail patient may herald a momentous transition toward greater homeostatic instability, disability and risk of death. ${ }^{11}$

Frailty is a common state preceding death. ${ }^{37}$ Two-thirds of frail patients have disabling trajectories at the end of life. ${ }^{37}$ In a recent populationbased study, $26.7 \%$ of deaths were associated with frailty ${ }^{38}$ Frailty is associated with high health service utilization, with most expenditures related to long-term care and in-patient care at the end of

Table 4: Summary of health-related quality of life

\begin{tabular}{|c|c|c|c|c|c|c|}
\hline \multirow[b]{2}{*}{ Quality-of-life measure } & \multicolumn{3}{|c|}{ Group; score, mean \pm SD } & \multicolumn{3}{|c|}{$p$ value* } \\
\hline & Frail & Not frail & $\begin{array}{c}\text { General } \\
\text { populationt }\end{array}$ & $\begin{array}{l}\text { Frail v. } \\
\text { not frail }\end{array}$ & $\begin{array}{l}\text { Frail v. general } \\
\text { population }\end{array}$ & $\begin{array}{l}\text { Not frail v. general } \\
\text { population }\end{array}$ \\
\hline At 6 mo & $n=67$ & $n=195$ & & & & \\
\hline EQ VAS & $52 \pm 22$ & $65 \pm 19$ & $79 \pm 16$ & $<0.001$ & $<0.001$ & $<0.001$ \\
\hline SF-12, physical health & $35 \pm 9$ & $37 \pm 7$ & $52 \pm 9$ & 0.1 & $<0.001$ & $<0.001$ \\
\hline SF-12, mental health & $33 \pm 7$ & $39 \pm 8$ & $48 \pm 11$ & $<0.001$ & $<0.001$ & $<0.001$ \\
\hline At $12 \mathrm{mo}$ & $n=59$ & $n=170$ & & & & \\
\hline EQ VAS & $54 \pm 23$ & $68 \pm 18$ & $79 \pm 16$ & $<0.001$ & $<0.001$ & $<0.001$ \\
\hline SF-12, physical health & $35 \pm 8$ & $38 \pm 7$ & $52 \pm 9$ & 0.005 & $<0.001$ & $<0.001$ \\
\hline SF-12, mental health & $34 \pm 7$ & $39 \pm 8$ & $48 \pm 11$ & $<0.001$ & $<0.001$ & $<0.001$ \\
\hline
\end{tabular}


life. ${ }^{38}$ Indeed, health expenditures for frail people increase 2.4-fold on average in the final 3 months of life. ${ }^{38}$ Consistent with these observations, frail patients in our study had longer stays in ICU and hospital, had more acquired disability and had higher hospital readmission rates than their nonfrail counterparts. Frail participants also had higher in-hospital and 12-month mortality. Moreover, we found graded increases in the risk of death associated with increasing severity of frailty.

We observed no differences between the frail and nonfrail patients in the intensity of treatment provided or in ICU mortality. These data suggest that frail patients, once admitted to ICU, received therapy commensurate with their illness severity, and perhaps only later had goals of care readdressed following a time-limited trial. ${ }^{39}$

\section{Limitations}

Our study has several limitations. First, the Clinical Frailty Scale, although a well-validated bedside assessment tool, ${ }^{3,10}$ has an inherent element of informed subjectivity. However, we believe we mitigated this by ensuring all research personnel were trained to use it systematically and were masked to the study hypotheses. This was reinforced by patients classified as frail having numerous features consistent with the frail phenotype. ${ }^{1,23}$

Second, we recruited participants after admission to ICU. Thus, we did not have reliable measures of health-related quality of life before admission, and all of our analyses were anchored to assessments that started in the ICU.

Third, we were unable to integrate dynamic functional measures such as mobility, grip strength and cognition before the development of critical illness that may have further informed on survival and trajectory relative to baseline. Similarly, we did not have markers of inflammation or nutritional status or other laboratory measures that might have helped with a mechanistic understanding of why frailty was associated with adverse events.

\section{Conclusion}

Frailty was common among critically ill adults aged 50 years or more and identified a vulnerable population at increased risk of adverse events, morbidity and mortality. Our findings suggest that routine assessment of frailty could provide more accurate prognostication and identify a vulnerable population that might benefit from follow-up and intervention.

\section{References}

1. Fried LP, Ferrucci L, Darer J, et al. Untangling the concepts of disability, frailty, and comorbidity: implications for improved targeting and care. J Gerontol A Biol Sci Med Sci 2004;59:255-63.

2. Clegg A, Young J, Iliffe S, et al. Frailty in elderly people. Lancet 2013;383:752-62.
3. Rockwood K, Song X, MacKnight C, et al. A global clinical measure of fitness and frailty in elderly people. CMAJ 2005; 173:489-95

4. Rockwood K, Song X, Mitnitski A. Changes in relative fitness and frailty across the adult lifespan: evidence from the Canadian National Population Health Survey. CMAJ 2011;183:E487-94.

5. Makary MA, Segev DL, Pronovost PJ, et al. Frailty as a predictor of surgical outcomes in older patients. J Am Coll Surg 2010;210: 901-8.

6. Kristjansson SR, Nesbakken A, Jordhoy MS, et al. Comprehensive geriatric assessment can predict complications in elderly patients after elective surgery for colorectal cancer: a prospective observational cohort study. Crit Rev Oncol Hematol 2010;76:208-17.

7. Dasgupta M, Rolfson DB, Stolee P, et al. Frailty is associated with postoperative complications in older adults with medical problems. Arch Gerontol Geriatr 2009;48:78-83.

8. Lee DH, Buth KJ, Martin BJ, et al. Frail patients are at increased risk for mortality and prolonged institutional care after cardiac surgery. Circulation 2010;121:973-8.

9. Lee JS, He K, Harbaugh CM, et al. Frailty, core muscle size, and mortality in patients undergoing open abdominal aortic aneurysm repair. J Vasc Surg 2011;53:912-7.

10. Sündermann S, Dademasch A, Praetorius J, et al. Comprehensive assessment of frailty for elderly high-risk patients undergoing cardiac surgery. Eur J Cardiothorac Surg 2011;39:33-7.

11. McDermid RC, Stelfox HT, Bagshaw SM. Frailty in the critically ill: a novel concept. Crit Care 2011;15:301.

12. Mitnitski AB, Graham JE, Mogilner AJ, et al. Frailty, fitness and late-life mortality in relation to chronological and biological age. BMC Geriatr 2002;2:1.

13. Lacson E Jr, Xu J, Lin SF, et al. A comparison of SF-36 and SF-12 composite scores and subsequent hospitalization and mortality risks in long-term dialysis patients. Clin J Am Soc Nephrol 2010;5: 252-60.

14. Kaarlola A, Tallgren M, Pettila V. Long-term survival, quality of life, and quality-adjusted life-years among critically ill elderly patients. Crit Care Med 2006;34:2120-6.

15. Elixhauser A, Steiner C, Harris DR, et al. Comorbidity measure for use with administrative data. Med Care 1998;36:8-27.

16. Johnston JA, Wagner DP, Timmons S, et al. Impact of different measures of comorbid disease on predicted mortality of intensive care unit patients. Med Care 2002;40:929-40.

17. Gnjidic D, Hilmer SN, Blyth FM, et al. Polypharmacy cutoff and outcomes: five or more medicines were used to identify community-dwelling older men at risk of different adverse outcomes. J Clin Epidemiol 2012;65:989-95.

18. Knaus WA, Draper EA, Wagner DP, et al. APACHE II: a severity of disease classification system. Crit Care Med 1985;13:818-29.

19. Vincent JL, Moreno R, Takala J, et al. The SOFA (Sepsis-related Organ Failure Assessment) score to describe organ dysfunction/ failure. On behalf of the Working Group on Sepsis-Related Problems of the European Society of Intensive Care Medicine. Intensive Care Med 1996;22:707-10.

20. de Rooij SE, Govers AC, Korevaar JC, et al. Cognitive, functional, and quality-of-life outcomes of patients aged 80 and older who survived at least 1 year after planned or unplanned surgery or medical intensive care treatment. JAm Geriatr Soc 2008;56:816-22.

21. Vest MT, Murphy TE, Araujo KL, et al. Disability in activities of daily living, depression, and quality of life among older medical ICU survivors: a prospective cohort study. Health Qual Life Outcomes 2011;9:9

22. Johnson JA, Pickard AS. Comparison of the EQ-5D and SF-12 health surveys in a general population survey in Alberta, Canada. Med Care 2000;38:115-21.

23. Gill TM, Allore HG, Holford TR, et al. Hospitalization, restricted activity, and the development of disability among older persons. JAMA 2004;292:2115-24.

24. Ehlenbach WJ, Hough CL, Crane PK, et al. Association between acute care and critical illness hospitalization and cognitive function in older adults. JAMA 2010;303:763-70.

25. Pandharipande PP, Girard TD, Jackson JC, et al. Long-term cognitive impairment after critical illness. $N$ Engl J Med 2013;369: 1306-16.

26. Rønning B, Wyller TB, Seljeflot I, et al. Frailty measures, inflammatory biomarkers and post-operative complications in older surgical patients. Age Ageing 2010;39:758-61.

27. Fairhall N, Sherrington C, Kurrle SE, et al. Effect of a multifactorial interdisciplinary intervention on mobility-related disability in frail older people: randomised controlled trial. BMC Med 2012; 10:120.

28. Shehabi Y, Chan L, Kadiman S, et al. Sedation depth and long-term mortality in mechanically ventilated critically ill adults: a prospective longitudinal multicentre cohort study. Intensive Care Med 2013; 39:910-8. 
29. Quinlan N, Marcantonio ER, Inouye SK, et al. Vulnerability: the crossroads of frailty and delirium. J Am Geriatr Soc 2011;59 (Suppl 2):S262-8.

30. Doig GS, Simpson F, Finfer S, et al. Effect of evidence-based feeding guidelines on mortality of critically ill adults: a cluster randomized controlled trial. JAMA 2008;300:2731-41.

31. Manias E, Williams A, Liew D. Interventions to reduce medication errors in adult intensive care: a systematic review. Br J Clin Pharmacol 2012;74:411-23.

32. Schweickert WD, Pohlman MC, Pohlman AS, et al. Early physical and occupational therapy in mechanically ventilated, critically ill patients: a randomised controlled trial. Lancet 2009;373:1874-82.

33. Ferrucci L, Guralnik JM, Studenski S, et al. Designing randomized, controlled trials aimed at preventing or delaying functional decline and disability in frail, older persons: a consensus report. $J$ Am Geriatr Soc 2004;52:625-34.

34. Rockwood K. What would make a definition of frailty successful? Age Ageing 2005;34:432-4.

35. Haas JS, Teixeira C, Cabral CR, et al. Factors influencing physical functional status in intensive care unit survivors two years after discharge. BMC Anesthesiol 2013;13:11.

36. Sprung CL, Baras M, Iapichino G, et al. The Eldicus prospective, observational study of triage decision making in European intensive care units: part I-European Intensive Care Admission Triage Scores. Crit Care Med 2012;40:125-31.

37. Gill TM, Gahbauer EA, Han L, et al. Trajectories of disability in the last year of life. N Engl J Med 2010;362:1173-80.

38. Fassbender K, Fainsinger RL, Carson M, et al. Cost trajectories at the end of life: the Canadian experience. J Pain Symptom Manage 2009;38:75-80.

39. Quill TE, Holloway R. Time-limited trials near the end of life JAMA 2011;306:1483-4.

Affiliations: Division of Critical Care Medicine, (Bagshaw, McDermid, Baig) University of Alberta Hospital, Division of Geriatric Medicine (Rolfson), Department of Medicine (Tsuyuki, Majumdar), Epidemiology and Research Coordinating Centre (Tsuyuki, Ibrahim), Division of Critical Care Medicine (Stollery), Grey Nuns Community Hospital, Division of Critical Care Medicine (Rokosh), Misericordia Community Hospital, Faculty of Medicine and Dentistry, University of Alberta, Edmonton, Alta.; Department of Critical Care Medicine (Stelfox, Artiuch), Faculty of Medicine, University of Calgary, Calgary, Alta.
Contributors: Sean Bagshaw, Thomas Stelfox, Robert McDermid, Darryl Rolfson, Ross Tsuyuki and Sumit Majumdar helped conceive and design the study and interpreted the data. Sean Bagshaw, Thomas Stelfox, Nadia Baig, Barbara Artiuch, Daniel Stollery and Ella Rokosh acquired the data. Sean Bagshaw and Quazi Ibrahim analyzed the data. Sean Bagshaw drafted the manuscript; all of the authors revised it critically for important intellectual content and approved the final version submitted for publication.

Funding: This study was supported by grants from the Canadian Intensive Care Foundation, the University Hospital Foundation and the Canadian Institutes of Health Research (CIHR grant no. MOP 111044). The funding agencies had no role in the design or conduct of the study, in the collection, management, analysis or interpretation of the data, or in the preparation, review or approval of the manuscript.

Sean Bagshaw holds a Canada Research Chair in Critical Care Nephrology and is a Clinical Investigator supported by Alberta Innovates - Healthx Solutions. Thomas Stelfox is supported by a New Investigator Award from CIHR and a Population Health Investigator Award from Alberta Innovates. Sumit Majumdar is a Health Scholar (supported by Alberta Innovates - Health Solutions and the Alberta Heritage Foundation for Medical Research) and holds the Endowed Chair in Patient Health Management (supported by the Faculties of Medicine and Dentistry and Pharmacy and Pharmaceutical Sciences, University of Alberta).

Acknowledgements: Participating centres and investigators: Edmonton sites: University of Alberta Hospital: Sean Bagshaw, Robert McDermid, Darryl Rolfson, Ross Tsuyuki, Nadia Baig, Quazi Ibrahim and Sumit Majumdar; Grey Nuns Community Hospital: Daniel Stollery; Misericordia Community Hospital: Ella Rokosh. Calgary sites: Foothills Medical Centre: Thomas Stelfox; Rockyview General Hospital: George Alvarez; Peter Lougheed Hospital: Luc Berthiaume. The authors acknowledge the coordinators whose work was essential to completion of this study: Tracy Davyduke, Maliha Muneer, Kristen Reid, Gwen Thompson, Robin Scheelar, Jennifer Barchard and Samantha Taylor. 